\title{
Comparative Analysis of Study Habits Between Males and Females
}

\author{
Nishmin Unwalla
}

\begin{abstract}
Study habits play a critical role in a student's life. Success or failure of a student depends on his/her own study habits. The effective and efficient way of learning depends on the study habits of the students. Study habits are important, as they influence the educational performance of the students. Good study habits are a prerequisite for good academic performance (Rabia, Mubarak, Tallat, \& Nasir, 2017).
\end{abstract}

The present study aims to look at the gender differences in the study habits of college students. The Study Habits Inventory, a tool developed by M.N.Pulsane and Anuradha Sharma was used for the purpose of this research. The inventory consists of 45 questions which were used to measure the study habits of students. Poor habits of study are one of the main causes of educational backwardness. This research was conducted to get a better understanding of the habits of study of college students. It will help the students provide basis for awareness and know how their current study habits affects their performance in examinations. It has been proven that gender is an important variable while researching on student's learning. The research was conducted among 80 males and 80 females. The results showed that there exists a significant difference between the study habits of males and females and further also revealed that females tend to have better study habits as compared to males.

\section{INTRODUCTION}

The American Journal of Psychology (1903) defines a 'habit', as, "a more or less fixed way of thinking, willing, or feeling acquired through previous repetition of a mental experience." In other words, a habit is simply a behavior that's repeated until it becomes automatic. Habit is a recurrent and many times unconscious pattern of behavior that is acquired through frequent repetition.

Study Habits is the amount and kinds of study routines which the student used during a regular period of study occurred in conducive environment (Ozsoy, Metacognition,Study habits and attitudes, 2009). We can say that study habits are regular practices adopted by a student to maximize his/her productivity, efficiency, and retention while preparing for a particular evaluation. (Amuda, 2006) reported that study habits are a systematic conscious effort to gather specific knowledge which is general towards a set standard. It is a behavior that is simply manifested without conscious effort on the part of the learner.
A student's academic performance is directly related to his study habits. (Dikko, 2008) discovered that there is significant relationship between study habit skills and academic performance. (Julius \& Evans, 2015) reported that study habits help promote effective learning and additionally high academic performance. Students are perpetually in search of educational success, the success of their academic performance is their ultimate goal.

When children go to higher classes, they find it difficult to keep up with their studies. But good study habits would not just help them study well but also improve their grades and academic performance. Good study habits include planning a specific time for studying, being organized, maintaining class notes, being attentive in class, reading the textbook, and finishing work before deadlines. Bad study habits include skipping classes, not completing the work assigned in class, playing video games or watching TV instead of studying. (Jafari, Aghaei, \& Khatony, 2019) found that study habit skills such as time management and note-taking have a significant impact on academic achievement. Several factors are accountable for poor study habits skills some of which include note taking techniques, poor time management, lack of clean study room which is devoid of litter and dust and dirt, lack of well ventilated room of study in a noiseless area, and an inability to remember what is taught, that is, inability to recall easily.

Majority of the students complain about other factors being responsible for their poor academic performance. They hardly ever look at their study techniques which result in their poor performance. Through this research students can get a better understanding of their study habits and take the necessary measures to improve it. They can recognize where they are going wrong and work upon it. It can also be helpful for parents and the teachers/professors to understand the study patterns of the student so that they can guide the students to study effectively.

Moreover 'Gender' is a significant factor to be noted while looking at study habits. Findings on gender difference in study habits have differed from one study to another. A study conducted by (Aluja \& Blanch, 2004) found that females had a higher score on the study habit measure. (Ossai, 2012) conducted a study which showed that significant difference existed in the study habits of the students on the basis of age and gender. On the other hand (Mushoriwa, 2009) conducted a study on Zimbabwe students in which he found no significant difference in the study habits of male and female students. Also gender was not found to be a notable determinant of study habits skills 
as reported by (Awabil, 2013). The main focus of this research is to analyse and compare the study habits of males with that of females to get an insight about the objective differences in study habits between them.

\section{LITERATURE REVIEW}

Schools are the miniature societies and teachers are the medium through which students derive quality education. But, in spite of onerous efforts by teachers, changes exist in the educational achievement of students. A research on secondary school students about their study habits and attitudes with respect to gender was conducted by (Laxmi \& Kaur, 2017). The research suggests that varied reasons such as concentration and attention, family environment etc. affect academic achievement of a student but the most crucial factor impacting the student's performance is study habits of students. So, the present study tries to investigate the study habits and attitudes of secondary school students with respect to gender. Data from 200 P.S.E.B and C.B.S.E. secondary school students was collected using the 'Study Habits and Attitude Scale' by (Mathur, 2002). Results of the study revealed that a significant distinction existed among secondary school students in relation to gender.

(Reena B. Tok and Boruwa, 2014) conducted a study on higher secondary students of Assam with respect to their stream and gender. The aim of this study was to seek out the variations in the study involvement between boys and girls belonging to commerce and science streams. The study also intended to determine the interaction effects of gender of students and stream of study on the study involvement of the students. The sample for the study constituted of 136 Higher Secondary students of two Colleges of Lakhimpur district of Assam. The Study Involvement Inventory by Dr. Asha Bhatnagar was used to measure study involvement of the students. Mean, Standard Deviation, Two-way ANOVA, ttest were used to determine the results of the study.

(Koki \& Abdullahi, 2014) conducted a study on college students of Yobe State University, Nigeria on the topic 'Gender Differences in Study Habit Skills'. The study aimed to find out whether any differences existed in study habit skills among undergraduate students of Yobe State University in relation to gender. Data was collected using the survey method. A sample of 200 undergraduate students belonging to Yobe State University, Nigeria was chosen using Simple Random technique. The hypothesis of the study was tested using the Pearson's Product Moment Correlation. The results found that the undergraduate students had significant differences in study habit skills with respect to gender.

(Rajendran S, 2009) conducted a study on high school students in Tamil Nadu on the topic "Are study habits gender biased?". Factors such as home environment, subject planning, note-taking habit, concentration and attentionspan, reading, examination preparation techniques, and school environment were investigated in the study. A standardized tool was used for the purpose of analyzing the data of the study. The finding of the study suggested that no significant distinction was found in the study habits between boys and girls.

(Mathur, 2002) developed a test to determine the study habits of the students. This test is intended to be used on school students, college and university students, individuals ranging from age $13+$ years to adulthood. It is useful for measuring the Study Habits and Attitudes of students and can be used on both males and females. It attempts to differentiate between good and poor study habits of students. It can prove to be useful to teachers and counselors as it helps determine the students' study techniques in a scientific way. The test constitutes 60 items. A high score indicates good study habits and proper attitudes, while a low score suggests poor study techniques.

A study was conducted by (Mukhoupadhay \& Sansanwal, 1963) to determine whether a significant relationship existed between study habits and academic achievements amongst college undergraduate students. A sample of 113 adolescent college students between the agerange of 17 to 22 years was chosen for the purpose of the study. The students belonged to the College of Home Science, Himachal Pradesh. Thorough analyses of the results suggested that a significant relationship existed between study habits and academic achievement. High achieving adolescents were found to have a better performance in recording, task orientation and comprehension. Some factors which were significantly related such as gender, age, family income and education were seen to have an effect study habits.

A study conducted by (Bhatnagar, 1982) aimed to examine some factors which impacted student involvement in studies. The investigation was undertaken to study some of the factors affecting the involvement in studies of Secondary School Students of Delhi. Decits (1975) Cognitive Theory of Intrinsic Motivation was the conceptual model of the study. Thirty seven factors classified as background, psychological and scholastic achievement variables were studied. 600 students of class X from 15 schools of Delhi were chosen for the study through Stratified Random Sampling. Data collection was done through a number of tests and analyzed using various univariate, bivariate and multivariate statistical techniques.

A Study of Relationship between Study Habits, Intelligence and Testing Anxiety was conducted among Senior Secondary School Students. In this study a sample of 150 senior secondary year students, studying in government and non-government schools was selected. (Patel, 1976) designed the study to determine and examine the significant differences amongst study habits, intelligence and test anxiety in senior secondary students studying in government and non-government schools. Descriptive correlation survey design methods were used in this study.

A study was conducted by (Fayombo, 2010) to investigate the differences in interest in schooling, study habits and attitude towards substance abuse between secondary school male and female students. 210 secondary 
school students between the age-range of 14-18 years were randomly selected from 4 secondary schools in Barbados as participants of the study. The instruments used were Student's Study Habit Scale, Attitudes towards SubstanceAbuse Scale and Student's Interest in Schooling Scale. Data analysis was conducted using percentages frequency counts and independent t-test. The results showed significant differences in the student's attitudes toward substance abuse, interests in schooling and study habits. The means of Females were higher as compared to Males.

A study conducted by (Shawwa, et al., 2014) aimed to determine the differences in studying habits of medical students with respect to gender. Previous research has shown that gender is an important variable in students learning. Male and Female medical students were given a self-administered questionnaire. A total of 359 students were taken in the study out of which $48.7 \%$ were male and $51.3 \%$ were female medical students. Many differences were found in the study habits, skills and approach between male and female students.

\section{* Objectives}

1. To compare the differences in study habits between males and females.

2. To analyze the study habits of male college students.

3. To analyze the study habits of female college students.

\section{* Hypothesis}

$\mathrm{H}_{1}$ - There is a difference in the study habits between males and females

$\mathrm{H}_{0}$ - There is no difference in the study habits between males and females

\section{METHODOLOGY}

\section{A. Tool Description}

'Study Habits Inventory' by M.N Pulsane and Anuradha Sharma (1971) has been used in this research. The instrument consists of 45 questions and is a self-report measure. The study habits of an individual cover mainly the techniques of learning, memory, the reading habits, preparation of time-schedule, evaluation etc. This inventory is aims to make the teacher, the student and the parents aware about certain good and conducive study habits which can help improve student's achievement.

Some of the items which formulate this inventory are:-

1) Budgeting Time- It is important to manage time while studying. A time schedule needs to be prepared and work needs to be completed within the allotted time periods. A record should also be maintained of the amount of work completed and the work which needs to be done. Also the student must determine the time period during which he/she can study optimally.
2) Physical Conditions for Study- The environment is an important variable which impacts study habits. The temperature, ventilation, illumination, noise, clean and comfortable surroundings etc. are some of the components of the physical environment. The place of study should be quiet and peaceful with minimum distractions. Also it should be well organized and should be uncluttered.

3) Memory- By improving the memory the student can retain information for a longer time period. And for this he needs to learn better. Revising the previously learnt material will help in remembering the information for a longer period of time.

4) Reading Ability- One must have good reading ability in order to study better. For this the speed of reading is an important factor. An individual can read faster when reading silently as compared to reading loudly. Also technical matter requires more time to be remembered. A student must try to understand the matter while reading it in order to retain it better.

5) Note taking- Taking class notes is an important aspect of the learning process. Making notes from textbooks can also prove to be beneficial. Paraphrasing in one's own words and highlighting important points is considered a good way of making notes. Incorporating note-taking behavior in daily life can help make this a habit.

6) Factors in Learning Motivation- The desire or the willingness to learn is one of the most crucial aspects, apart from an individual's ability to learn. Genuine interest in learning can help the individual retain information for a longer time-period.

7) Taking Examinations- While taking examinations use of simple language is preferable. The headings and subheadings must be written legibly in a proper manner and important words and phrases must be highlighted.

i. Preparation for examination- A time schedule should be drawn up and more time and attention must be given to weaker subjects.

ii. Use of Examination Results- The results can help a person discern his strong points as well as his weak points.

8) Health- It is necessary to maintain good health to be able to perform well in exams.

\section{B. Variables}

$>$ Dependent- Study habits

$>$ Independent- Males and Females

\section{Sampling}

> Sample Size- The research is a comparison between study habits of males and females so a total of 160 undergraduate students were selected for the study out of which 90 were males and 70 were females.

> Sampling Technique- Data collection has been done by the technique of Stratified Random Sampling. A 'stratified random sampling' involves dividing the whole population into homogeneous groups which are called strata. Random samples are then selected from each stratum. 
ISSN No:-2456-2165

\section{RESULTS AND FINDINGS}

The total of 160 undergraduate students comprising of 90 males and 70 females have been chosen for this study.

\begin{tabular}{|c|c|}
\hline \multicolumn{2}{|c|}{ Descriptive Statistics } \\
\hline Mean & 53.40625 \\
\hline Standard Error & 0.746969605 \\
\hline Median & 53 \\
\hline Mode & 49 \\
\hline Standard Deviation & 9.448501179 \\
\hline Sample Variance & 89.27417453 \\
\hline Kurtosis & -0.028460637 \\
\hline Skewness & -0.019807955 \\
\hline Range & 50 \\
\hline Minimum & 28 \\
\hline Maximum & 78 \\
\hline Sum & 8545 \\
\hline Count & 160 \\
\hline
\end{tabular}

Table 1:- Descriptive Statistics

\begin{tabular}{|c|c|}
\hline \multicolumn{2}{|c|}{ Descriptive Statistics: Males } \\
\hline Mean & 50.56666667 \\
\hline Standard Error & 0.946779811 \\
\hline Median & 50.5 \\
\hline Mode & 49 \\
\hline Standard Deviation & 8.981941934 \\
\hline Sample Variance & 80.6752809 \\
\hline Kurtosis & 0.05905443 \\
\hline Skewness & 0.029440361 \\
\hline Range & 46 \\
\hline Minimum & 28 \\
\hline Maximum & 74 \\
\hline Sum & 4551 \\
\hline Count & 90 \\
\hline
\end{tabular}

\begin{tabular}{|c|c|}
\hline \multicolumn{2}{|c|}{ Descriptive Statistics: Females } \\
\hline Mean & 57.05714286 \\
\hline Standard Error & 1.053022017 \\
\hline Median & 58.5 \\
\hline Mode & 52 \\
\hline Standard Deviation & 8.810214287 \\
\hline Sample Variance & 77.61987578 \\
\hline Kurtosis & 0.169086164 \\
\hline Skewness & -0.072433207 \\
\hline Range & 46 \\
\hline Minimum & 32 \\
\hline Maximum & 78 \\
\hline Sum & 3994 \\
\hline Count & 70 \\
\hline
\end{tabular}

Table 2:- Descriptive Statistics for Males and Females

Mean is nothing but the 'Average' of the population. Here in Table 2 which compares the descriptive statistics of males and females we see that the mean of females is higher compared to men. Through this we can infer that the study habits of females are better than males. "A study conducted by (Aluja \& Blanch, 2004) found the academic achievement of females higher compared to males. These could be explained by the fact that females showed higher aspiration level, a more socialized personality pattern and better study habits". A study conducted by (Prima, 2007) highlights that girls have better study habits. (Duckworth \& Seligman, 2006) in their study observed that girls are more selfdisciplined compared to boys. They found that girls are more adept at "reading test instructions paying attention to a teacher completing homework and persisting on long-term assignments despite boredom and frustration." "Also female college students are far more likely than males to jot down detailed notes in class, reproduce what professors say more accurately, and remember lecture content better than males (Reddington, 2011)."

As seen in Table 2 the mean of females is higher compared to men, which suggests that the study habits of females are better than males. This is further proven by comparing some of the responses of males and females from the survey conducted, which are illustrated in form of piecharts. 


\section{Q1. I study everyday}
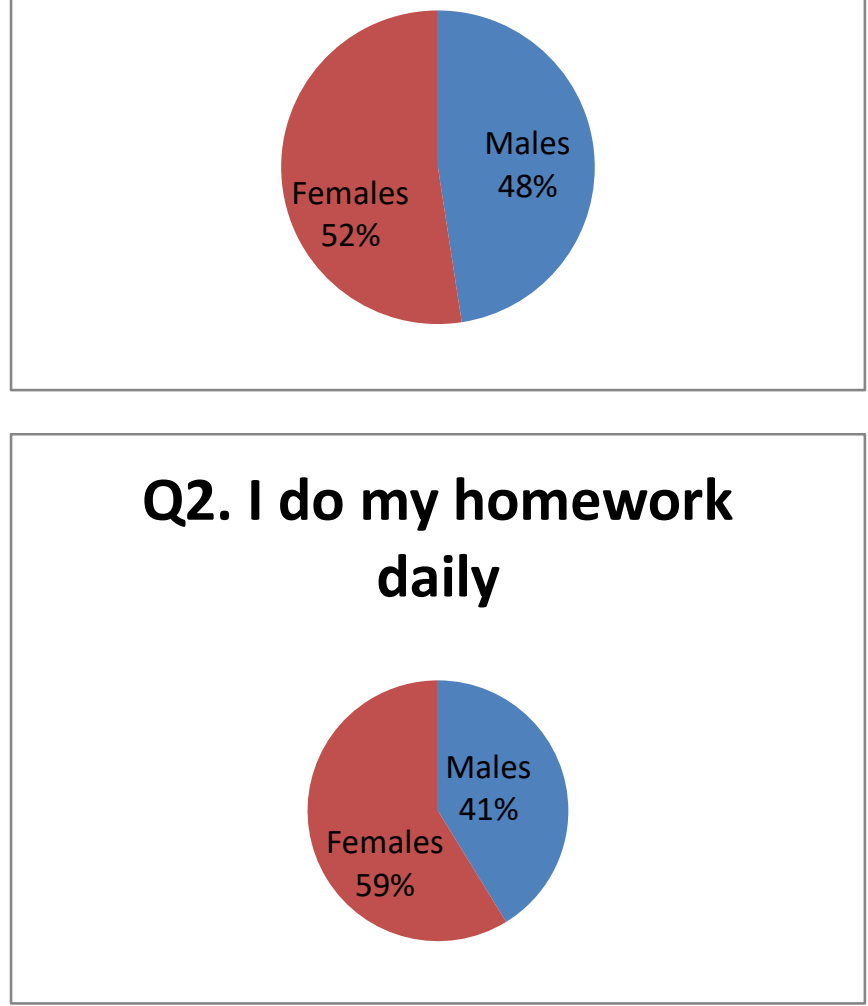

\section{Q3. During the classroom teaching, I take down notes very sincerely}

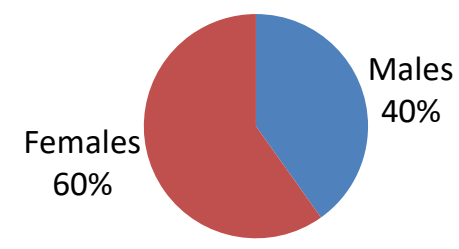

\section{DISCUSSION AND CONCLUSION}

The findings of the study suggest that a significant difference exists in the study habits of male and female students. From Table 1.2 it can be inferred that the study habits of females is better compared to males. It has been observed that females are more self-disciplined, tend to complete work on time and are more attentive compared to males. Part of this could also be gender differences in cognitive development and characteristics. Female brains tend to mature about 1-2 years faster than male brains, especially during teen years. Females tend to be better at reading and writing tasks. This research has primarily been conducted to find out whether there is any difference in study habits of males and females. From the results and findings it would be safe to conclude that there exists a significant difference in study habits of males and females and females tend to have better study habits compared to males.

\section{REFERENCES}

[1]. Aluja A. \& Blanch, A. (2004). Socialized personality scholastic aptitudes, study the habits and academic achievement. Exploring the link European. Journal of Psychological Assessment, 137-147.

[2]. Aluja, A., \& Blanch, A. (2004). Socialized Personality, Scholastic Aptitudes, Study Habits and Academic Achievement. Exploring the Link. European Journal of Psychological Assessment.

[3]. Amuda, G. (2006). Relationship between study habit patterns and academic achievement among students. Unpublished Masters Dissertation.

[4]. Awabil, G. K. (2013). Effect of study, and self reward skills. The Counsellor, 39-46.

[5]. Bhatnagar, A. (1982). Study Involvement Inventory. National Psychological Corporation.

[6]. Dikko, S. (2008). An analysis of different study habits and their effect on academic performance of Pre- NCE students in Federal College of Education, Katsina. Gabarau Journal of Education, 113-120.

[7]. Duckworth, A. L., \& Seligman, M. E. (2006). SelfDiscipline Gives Girls the Edge: Gender in SelfDiscipline, Grades, and Achievement Test Scores. Journal of Educational Psychology, Volume 98 No.1, 198-208.

[8]. Fayombo, G. (2010). Gender differences in study habit, interest in schooling and attitude towards substance abuse among secondary school adolescents in Barbados. Carribean Research Education Journal, $87-95$

[9]. Jafari, H., Aghaei, A., \& Khatony, A. (2019). Relationship between study habits and academic achievement in students of medical sciences in Kermanshah-Iran. Advances in Medical Education and Practice, 637-643.

[10]. Julius, M., \& Evans, A. (2015). Study of the relationship between study habits and academic achievement of students: A case of Spicer Higher Secondary School, India. International Journal of Educational Administration an Policy Studies, 134141.

[11]. Koki, A. T., \& Abdullahi, U. (2014). Gender Differences in Study Habit Skills of undergraduate students of Yobe state university. Knowledge Review, Vol 31 No.2.

[12]. Laxmi, V., \& Kaur, P. (2017). Study Habits and Attitudes among secondary school students with respect to gender. International Journal of Information Movement, 106-111.

[13]. Mathur, C. P. (2002). Manual for test of study habits and attitudes. Agra: National Psychological Corporation.

[14]. Mukhoupadhay, \& Sansanwal. (1963). Study Habits Inventory. Nation Psychological Corporation. 
[15]. Mushoriwa, T. (2009). The study strategy performance function among students in three teachers colleges in Masvingo and Harae, Zimbabwe. . Journal of Education and Social Sciences, 153-166.

[16]. Ossai, C. M. (2012). Age and gender differences in study habits: a framework for proactive counselling against low academic achievement. J. Edu. Soc. Res., 67-73.

[17]. Ozsoy, M. (2009).

[18]. Ozsoy, M. (2009). Metacognition,Study habits and attitudes. International Electronic Journal of Elementary Education, 154-166.

[19]. Patel, B. (1976). Manual for Study Habits Iventory. National Psychological Corporation.

[20]. Prima, R. (2007). A Study of Study Habit and Achievement Motivation towards Academic Achievement among XII Higher Secondary School Students. Dissertation,

[21]. Rabia, M., Mubarak, N., Tallat, H., \& Nasir, W. (2017). A Study on Study Habits and Academic Performance of Students. Internationa Journal of Asian Social Science, 891-897.

[22]. Rajendran S, R. A. (2009). Are Study habits Gender Biased? Edutracks, 41-44.

[23]. Reddington, L. A. (2011). Gender difference variables predicting expertise in lecture note-taking. Columbia University, New York: (Unpublished doctoral dissertation).

[24]. Reena B. Tok and Boruwa, S. (2014). A study involvement of higher secondary students with regard to their gender and stream of study. International Journal of Multidisciplinary Approach and Studies, 124-131.

[25]. S., M. A. (2006). Study Habit Pattern of Secondary school students in Adamawa and Borno State. unpublished project of University of Maidugiri.

[26]. Shawwa, L., Abdulrhman , A. A., Algethami, A., BaghJaf, S., Abushanab, J., Merdad, A., et al. (2014). DIFFERENCES IN STUDYING HABITS BETWEEN MALE AND FEMALE MEDICAL STUDENTS OF KING ABDULAZIZ UNIVERSITY. Egyptian dental journal, 1687-1693. 